\title{
Hurricane Matthew Impacts to Marine and Coastal Biodiversity on Southern Coast of Dominican Republic
}

\author{
Enrique Pugibet Bobea, Francisco Geraldes Siraguza, Luis Almánzar Regalado, Héctor Ramírez Crespo and \\ Valentín Rivas Grullon \\ Marine Biology Research Center (CIBIMA), Faculty of Sciences, Universidad Autónoma de Santo Domingo (UASD), Santo Domingo
} 10106, República Dominicana

\begin{abstract}
A rapid environmental assessment was conducted by the staff of Marine Biology Research Center (CIBIMA), Faculty of Sciences, Universidad Autónoma de Santo Domingo (UASD) on the southern coast of the Dominican Republic, to evaluate the effects of the hurricane Matthew on October 3, being the 14th storm of the year 2016 for the Caribbean region. The observations were carried out two weeks after the storm hit. These observations included coastal ecosystems, such as marshes, beaches, lagoons, wetlands, mangrove forests, nearshore sea grasses and coral reefs. The evaluation included observations on the magnitude of the distresses and levels of destruction — changes, produced by the intense weather and upset climate from the storm. The data gathered were recorded following a categorization of impacts. It also included a description of the different coastal communities after being impacted and affected by the storm.
\end{abstract}

Key words: Hurricane Matthew, hurricane impacts, coastal biodiversity, south of Dominican Republic.

\section{Introduction}

Hurricanes or tropical cyclones are weather events of the planet; its size and strength affect and create distinctive contrast to the average mild weather here found. Its effects on the environment usually have been described as harmful, because of its impetuous dynamism in the steering land-ocean atmosphere system. "Hurricanes", as they were called by the Taíno or Siboney culture of the Antilles, which means "God of the winds" or "God of all evil", always caused fear and respect for natives, since their villages and areas of cultivation were severely affected by the strong winds and torrential rains that are associated with the hurricanes. Thus, the horror for hurricanes resulted in veneration and reverence for these phenomena. The fear of hurricanes was always present among many Mesoamerican groups during the warm period of a year [1-3].

On September 22, 2016, the U.S. National

Corresponding author: Enrique Pugibet Bobea, M.Sc., research fields: marine biology and fishery management.
Hurricane Center (NHC) announced the formation of a tropical low-latitude wave at the eastern end of the Atlantic, with potential further development propelling westward to the northwest. In a zone of high pressure to the east of the Bermuda, the wave acquired organization, establishing a great zone of convection around the center and becoming a tropical cyclone. On September 27, a reconnaissance aircraft, "hurricane hunters", found winds with tropical storm force. On September 28, another "hurricane hunters" finds winds of $60 \mathrm{mph}(95 \mathrm{~km} / \mathrm{h})$. The NHC begins warning about tropical storm Matthew at 15:00 GMT on that day. Just a few hours after being classified as a tropical storm, Matthew moved to St. Lucia and entered the Caribbean Sea. Next day, on September 29, despite a moderate southwest shear, Matthew became a Category 1 hurricane on the Saffir-Simpson scale. Two days later, Matthew reached Category 4. Hurricane Matthew was the fourteenth storm of the Atlantic and the fifth hurricane of 2016 season [4]. Matthew became a powerful Category 5 hurricane on September 30, and then descended into Category 4 . 
On October 3, 2016, Mathew practically parked off the southern coast of the Hispaniola Island, with winds of Category 4 hurricane with $30 \mathrm{mph}$ to 145 mph winds, and presenting an increase pattern as it reduced distance from the coastal zone. It is considered as the strongest hurricane that has affected the Caribbean area since hurricane Felix in 2007.

The Marine Biology Research Center (CIBIMA) of the Faculty of Sciences at the Universidad Autónoma de Santo Domingo (UASD) has an ongoing program, evaluating the relations between coastal and marine biodiversity and ecosystems, and its response of human impacts from development, as well as those from natural origin. As part of this ongoing research, recognizing hurricanes and their impacts are considered among the natural phenomena of greater importance for coastal and marine environment. And with the objective of conducting a rapid report of the effects of Matthew, field visits were made to the southern coast of Dominican Republic, and description on the conditions left and the characteristic of the impact received was recorded for these different coastal communities.

\section{Materials and Methods}

Hurricane Matthew and its impact to coastal environment were considered as important natural phenomena to be evaluated. In mid-October of 2016, visits were made to coastal areas on the southern coast of the Dominican Republic, from Haina river, San Cristóbal province to Pedernales river, Pedernales province, with the objective of conducting a rapid environmental assessment of the effects of Matthew. The locations inspected are presented on the map (Fig. 1). This portion of the coast was evaluated within $15 \mathrm{~d}$ after the hurricane Matthew passing. Visiting and collecting data and information of the beaches, dunes, marshes, coastal lagoons (wetlands), mangroves-coastal woodlands and nearshore sea grasses and reef systems were found in the region [5, 6]. For this evaluation, an impact analysis was carried using a typology of impacts that assigns values according to its intensity, extension, the moment in which manifests and its persistence (Table 1). Also, it was evaluated the level of distress/affectations found for each site (Table 2). Monitoring and evaluation were carried out following methodology and formal environmental impact assessment process, basically addressing those changes affecting biodiversity and coastal landscape [7-10].

\section{Results and Discussion}

These extreme atmospheric phenomena are characterized by intense winds, breaking wave surges and abnormally created currents. The effects of these combined forces had important impacts and created a difference in the environmental conditions where these occurred, consequently affecting the composition and structure of marine and coastal biodiversity there found. It was noted an effect over mangroves ecosystems, coastal vegetation, low-lying floodplains (wetlands) and sandy beaches. Submerged coastal marine ecosystems, such as sea grasses and coral reefs, were also affected, of which the most noticeable was the removal and fracture of seabed structures, organisms and inhabitants, including hard corals, soft corals and sponges, which were detached from their benthic settings and dragged by currents and deposited on the shore of beaches and coastline. It was also found changes in water quality, mainly the increased turbidity created by the suspension of sediments and modification and the secondary effect of alterations of the physic-chemical composition of the water column. This synergetic effect caused devastations on the affected areas. There, ecosystems had to readapt and transform to this new settings and distributions and abundances of organisms with new patterns, different from those previously established. After a hurricane, the main agents of destruction usually carry on for a long time, including 


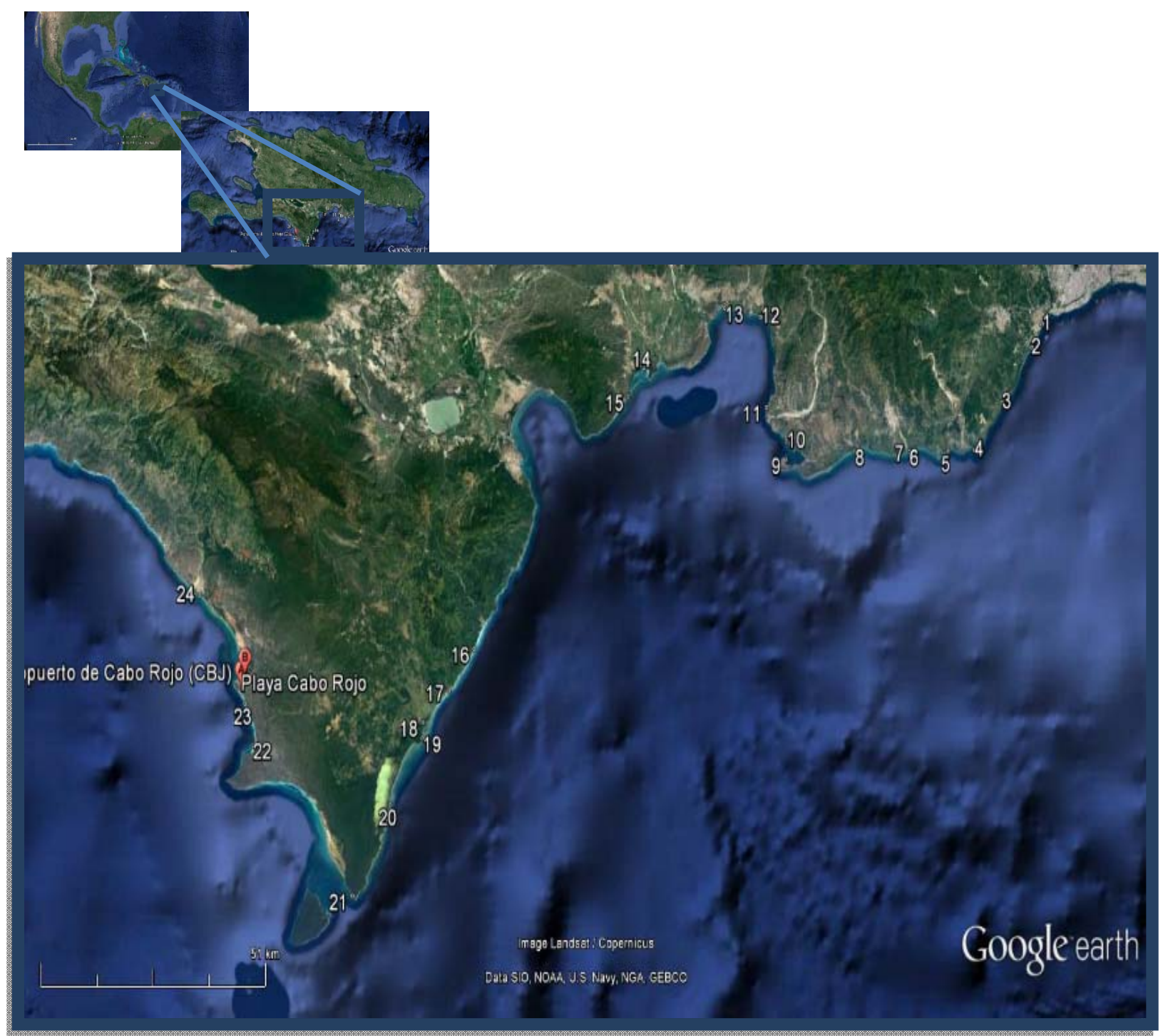

Fig. 1 Map of south coast of the Dominican Republic, coastal localities inspected for impact assessment by hurricane Matthew during the month of October 2016.

1: Playa Los Gringos; 2: ecological park of Nigua; 3: Playa Najayo; 4: Playa Palenque; 5: Nizao beach; 6 and 7: Paya and Los Almendros; 8: La Poza beach; 9: Punta Caballera (Salinas); 10: Los Corbanitos beach; 11: Palmar beach of Ocoa; 12: Caracoles beach; 13: Tortuguero beach and Monte Rio beach and Salinas de Azua; 14: Puerto Viejo beach; 15: Caobita beach; 16 and 17 : Enriquillo and Patos beaches; 18 and 19: Carmen and Punta Blanca beaches; 20 and 21: Mosquea and Bucan beaches; 22: Bahía de las Aguilas beach; 23: beaches and mangroves of Cabo Rojo; 24: Playa de Pedernales. 
Table 1 Different typology and values assigned to environmental impacts.

\begin{tabular}{ll}
\hline Typology of impacts & Values \\
\hline \multirow{3}{*}{ Intensity: degree of action impact } & Very high: modification of the fundamental processes, almost total destruction; \\
& High: effect with alteration of some factors; \\
& Medium: average impact effects on some factors; \\
& Lower: effects with minimal damage. \\
& Critical: situation that occurs will be critical; \\
& Total: effect manifests itself in a widespread manner; \\
& Extreme: effect is detected in much of the media; \\
Extension: area of influence of the impact & Partial: effect with measurable impact; \\
& Punctual: localized effect. \\
& Critical: when impact occurs, it is shocking; \\
& Immediate: impact is assimilated in the short term; \\
Moment: account of the impact period & Latent: the effect manifests itself after some time. \\
& Permanent: indefinite alteration of structure or function; \\
Persistence: time that the effect would remain & Persistent: $4-10$ years; \\
& Temporal: 1 -3 years; \\
& Brief: < 1 year. \\
\hline
\end{tabular}

Table 2 Levels of affectation impacts/visual distress affectation.

Level of impacts/visual distress affectation

High (H): these can potentially adversely affect the natural and ecosystem function and its sustainability. Could have strong synergistic or cumulative effects and likely have significant adverse social impacts on peoples.

Substantial (S): these could substantial affect the natural and ecosystem function and its sustainability. Could have synergistic or cumulative effects and have the potential to contribute directly to increased social fragility.

Moderate (M): these could moderately affect the natural and ecosystem function and its sustainability. Could have or not have synergistic or cumulative effects with other ecosystems and uses. May also have moderate adverse effects on vulnerable groups. Low (L): these have minimal effects on the natural and ecosystem function and its sustainability. Could have or not have synergistic or cumulative effects with other ecosystems and uses. May also have low adverse effects on vulnerable groups.

suspended sediments nutrients pollution, removal of herbivores and carnivores, as well as debris accumulations on the bottom of the seas, such as corals, shells and trunks. Being a hurricane, a natural event, the tropical coastal biodiversity and ecosystems have adapted to them [11-14]. In general, the coastal zones and the marine ecosystems in the Dominican Republic have suffered and continue suffering impacts, degradation, as well as a reduction of their ecosystem functions, due to the urban, agro-industrial and industrial development, all of these later are from anthropogenic origin.

During the present evaluation, removal of sand and erosion of beach berms were documented, being noticeable to find the differences between shores protected and those unprotected shores by reefs structures. Also, storm surge effects were documented, being the most noticeable the accumulation and deposits on the back portion of sand dunes, this in there the debris composition consisted mainly of human generated solid wastes, among residual of corals, sea grasses and algae remains. Table 3 summarized the level of distress found during the site inspection; following there is a description on the same order visited of the level of impacts found. For each community, the typology of impacts was also described.

In the province of San Cristóbal, in Playa de Los Gringos, the effects of the storm surge were visible with the increase and accumulation of solid waste (trash, mainly plastic) in the upper part of the dune, reaching $10 \mathrm{~m}$ from shore. Impacts at this location were documented as being lower, punctual, immediate and brief.

On the shores of the ecological park of Nigua were large accumulations of sand, solid waste, either from organic origin, as well as plastics along the rocky shores (beach-rock). There were visible effects of water displaced by waves over the coastal slope, causing swampland flooding, loss of the mangroves trees and other coastal vegetation. There were remnants of sea grass, detached from the bottom and 
Table 3 Level of distress found during the site inspection.

\begin{tabular}{|c|c|c|c|c|c|c|}
\hline \multirow[b]{2}{*}{ Coastal site name } & \multirow[b]{2}{*}{ Position UTM: 19Q } & \multicolumn{5}{|c|}{ Ecosystems/distress affectation levels } \\
\hline & & $\begin{array}{l}\text { Sandy } \\
\text { beaches }\end{array}$ & $\begin{array}{l}\text { Rocky } \\
\text { beaches }\end{array}$ & Swamps & Mangroves & $\begin{array}{l}\begin{array}{l}\text { Shore cliffs } \\
\text { (terrain) }\end{array} \\
\end{array}$ \\
\hline 1. Los Gringos & 391925.69m E, 2035985.81m N & $\mathrm{L}$ & - & - & - & - \\
\hline 2. Nigua & $389300.07 \mathrm{~m} \mathrm{E}, 2032022.37 \mathrm{~m} \mathrm{~N}$ & M & $\mathrm{L}$ & M & M & - \\
\hline 3. Najayo & 383013.88m E, 2023763.51m N & M & $\mathrm{L}$ & - & - & - \\
\hline 4. Palenque & 376646.83m E, 2016571.65m N & $\mathrm{L}$ & - & $\mathrm{L}$ & - & - \\
\hline 5. Nizao & $372465.68 \mathrm{~m} \mathrm{E}, 2016635.00 \mathrm{~m} \mathrm{~N}$ & $\mathrm{~L}$ & - & $\mathrm{L}$ & - & - \\
\hline 6. Almendros & 363223.62m E, 2016537.10m N & $\mathrm{L}$ & - & $\mathrm{L}$ & - & - \\
\hline 7. La Poza & $350655.98 \mathrm{~m} \mathrm{E,} \mathrm{2016340.25m} \mathrm{N}$ & M & - & - & - & M \\
\hline 8. Punta Caballera & 336255.62m E, 2025941.01m N & $\mathrm{L}$ & - & - & - & $\mathrm{L}$ \\
\hline 9. Corbanitos & 336212.20m E, 2018366.85m N & $\mathrm{L}$ & $\mathrm{L}$ & $\mathrm{L}$ & $\mathrm{L}$ & $\mathrm{L}$ \\
\hline 10. Palmar de Ocoa & 332002.66m E, 2023170.39m N & $\mathrm{L}$ & - & M & $\mathrm{L}$ & M \\
\hline 11. Caracoles & 328485.41m E, 2037362.94m N & $\mathrm{L}$ & $\mathrm{L}$ & $\mathrm{L}$ & $\mathrm{L}$ & - \\
\hline 12. Tortuguero & 321354.14m E, 2038233.71m N & $\mathrm{L}$ & $\mathrm{L}$ & $\mathrm{L}$ & $\mathrm{L}$ & - \\
\hline 13. Monte Rio & $319350.27 \mathrm{~m} \mathrm{E}, 2036357.70 \mathrm{~m} \mathrm{~N}$ & $\mathrm{~L}$ & - & $\mathrm{L}$ & $\mathrm{L}$ & $\mathrm{L}$ \\
\hline 14. Salinas Azua & 315644.08m E, 2029471.05m N & - & $\mathrm{L}$ & $\mathrm{L}$ & - & M \\
\hline 15. Puerto Viejo & $305761.70 \mathrm{~m} \mathrm{E}, 2029741.70 \mathrm{~m} \mathrm{~N}$ & M & $\mathrm{L}$ & $\mathrm{L}$ & $\mathrm{L}$ & - \\
\hline 16. Caobita & 302420.07m E, 2026013.31m N & $\mathrm{L}$ & - & $\mathrm{L}$ & $\mathrm{L}$ & $\mathrm{L}$ \\
\hline 17. Patos & $268983.96 \mathrm{~m} \mathrm{E}, 1987089.90 \mathrm{~m} \mathrm{~N}$ & - & $\mathrm{L}$ & $\mathrm{L}$ & - & $\mathrm{L}$ \\
\hline 18. Carmen & $257669.67 \mathrm{~m} \mathrm{E}, 1975402.32 \mathrm{~m} \mathrm{~N}$ & $\mathrm{~L}$ & - & $\mathrm{L}$ & M & - \\
\hline 19. Mosquea & $250232.47 \mathrm{~m} \mathrm{E}, 1962352.48 \mathrm{~m} \mathrm{~N}$ & $\mathrm{~L}$ & - & - & - & - \\
\hline 20. Aguilas & 221287.38m E, $1972454.82 \mathrm{~m} \mathrm{~N}$ & M & $\mathrm{L}$ & M & $\mathrm{L}$ & $\mathrm{L}$ \\
\hline 21. Cabo Rojo & $218102.28 \mathrm{~m} \mathrm{E}, 1982280.81 \mathrm{~m} \mathrm{~N}$ & M & $\mathrm{L}$ & M & M & $\mathrm{L}$ \\
\hline 22. Pedernales & 209335.96m E, $1995453.30 \mathrm{~m} \mathrm{~N}$ & M & M & M & M & $\mathrm{L}$ \\
\hline
\end{tabular}

L: low; M: moderate.

dispersed on the shore, mainly Syringodium sp. and to a lesser extent Thalassia sp. In studies, it was suggested that the pastures of Thalassia may be more fragile due to their shape and epiphytic cover and that the destruction of these by the impact of hurricanes can be of tens of square kilometers of pastures, although there does not seem to be a direct relationship between growth form and susceptibility to storm surge or sedimentation [15]. Impacts were described as medium, partial, immediate, and temporary. In Playa Najayo, the breaking waves caused damage to the coastal structures and loss of beach sand due to erosion. Impacts were lower, punctual, immediate and brief for this location. At Playa Palenque, it was found that the surf effects on the coast reached $100 \mathrm{~m}$ on the back slope of the dry beach, generating important destruction of the beach dune, as well as flooding of the posterior berth with sea water, affecting structures and weakening the foundations of road walls. Storm swells generated materials were transported, including rocks and corals that modified the beach profile. The effect of waves and water movements on sediment dynamics was visible even two weeks after the event. The hurricane also caused damage to small buildings that collapsed. There were remains of coastal growing trees (almonds, beach grapes), as well as plastic and organic solid waste accumulations on shore. Impacts were described as lower, partial, immediate and temporary. The Punta Palenque fringe reef, about $5 \mathrm{~m}$ deep, consists of stony corals, mainly Porites spp., Monstastrea spp., Agaricia spp. and Millepora spp. on a hard substrate, in a high energy zone. At this depth, the effect of the surf on corals was observable; some were detached and dragged by the swell, although the impact in this zone was defined as low to medium. In accordance 
with what has been assessed, corals cemented on a solid substrate, regardless of colony size and shape, can withstand waves or cyclone intensity and that the swell would only impact free corals or those of weak fixation $[16,17]$. Data from other authors have found that there is a variation in the growth form of coral colonies related to hurricane impacts adaptation. The position, orientation and depth of the substrate are also important issues to be taken into account [18-20]. In Peravia province, at Nizao beach, waves impacted on the dune, with significant loss of sand and overflows of swamps with sea water. Interviewed fishermen complained about the existing fishing difficulties. After the hurricane passing, they claim that waves and currents have altered the sea bottom conditions, claiming that most of the refuges and sites were their customary use for fishing grounds, no longer producing fishing. Hurricane impact on pelagic or reef patches is very complex and can be perceived up to a year later as marked differences remain [21]. After the impact of a cyclone, cryptic fish species feed near the reef and serve as food for carnivorous fishes, thus increasing their population. Species, such as damsel's fish (Stegastes spp.) become more abundant, due to the disappearance of algae mats, and reduce their territorial aggressiveness for a period. Parrotfish (Scarus spp.) reduce their numbers within the schooling. Usually, fish move to deeper water in the event of strong waves. This also increases difficulty to catch. Also to be considered is the damage of fishing gear (nets and traps), mislaid boats and beach line modification for boats access and landings. For this coastal area, the impacts were considered lower, partial, immediate and temporary.

In the coast of Paya and Los Almendros beaches, the effects of the surf on the coast generated remarkable erosion, affecting dunes and causing damages to structures, and deteriorated some buildings and walls foundations. There was visible beating of the beach line due to erosion caused by waves. There were remains of sea grasses
(Syringodium sp., Thalassia sp.) detached from sea bottom and dispersed onto shore. In addition, the breaking surf caused damages to structures of the dune, impacting coastal trees (almonds, beach grapes), with harming effects on the overall scenery and aesthetics of the landscapes by water displacement. The increased turbidity of the sea here was observed due to the sediment loads and discharges from Bani river and the beating of waves eroding the shoreline. The impact for this area is considered to be low to medium, partial, immediate and temporary. At La Poza beach, there were impacts of waves and the displacement of sea water, affecting the sandy cliff with loss of a significant portion, adjacent to coastal land with detriment effects on the seaside vegetation (button mangroves, almonds, beach grapes, cambrón). The large waves generated here transported large boulders of rocks, as well as modified the beach profile and structure. Large quantities of sea grasses (Syringodium sp., Thalassia sp.) were detached from the sea floor and accumulated on the shore. The effect of waves and water movements on sediment dynamics was still observable two weeks after the hurricane passing. Impacts on fishing activities were caused by migration of reef and pelagic fish of commercial importance. It was also reported by fisher that the hurricane damaged their fishing gear (nets and traps) and boats. The impact for the community is medium to high, partial, immediate and permanent.

Punta Caballera (Salinas), where a popular public beach is located, was affected by sea surge that overpassed existing installations. Besides, the sea water runoff affected the mangroves and other seashore vegetation. Impact on a few shallow hard corals was also observed. The impact was low to medium, partial, immediate and brief. At Los Corbanitos beach, there was swell damage to the coastline, water movement reached $10 \mathrm{~m}$ into the beach slope, contributing with sand and coral pieces and fragments into the dune. The impact was considered lower, partial, immediate and brief. 
In the Azua province, at the municipality of Palmar beach of Ocoa, impacts of the ocean surge and waves covered the entire existing dune, reaching a distance of more than $50 \mathrm{~m}$, carrying and integrating materials, mainly rocks and gravel, which modified the beach profile. Breaking waves and wind caused damage to coastal structures (piers, gazebos, walls and coastal roads). Impacts on fishing of pelagic fish species were reported, an imbalance was created due to the loss of refuge for cryptic species, becoming prey for the carnivore species, increasing their presence near shore. Catch of lobsters increased, apparently due to the loss of refuge and displacement, openly in the sea bottom. The overall impact reported here can be classified from low to medium, partial, immediate and persistent. At Caracoles beach, the large swells aggravated beach erosion, as well as flooded large areas of coastal vegetation, reaching more than $50 \mathrm{~m}$ inland, finding there rock deposits, dead sea grasses, algae and corals remains. The effect of waves and the movements of the water on the dynamics of the sediments were visible throughout the marine area. The impact found was considered here as low to medium, partial, immediate and brief.

At Tortuguero beach, the waves generated important coastal erosion and loss of soil. Wetlands in the area immediate behind the dune were flooded with seawater; mangroves and swamp trees were partially defoliated and some trees were lying down. The impact here found is low to medium, partial, immediate and brief. At Monte Rio beach, the beach erosion and garbage accumulations were evident, such as plastics, as well as organic wastes. The impact here found is low, partial, immediate and brief. At the site called the Salinas de Azua, damage found was mainly due to wind, rain and surface runoff effects. Flooding of the evaporation lagoons for salt production and impacts to dry forest can be reported as the main damage here occurred. The impact was established as low, partial, immediate and brief.

At Puerto Viejo beach, erosion was found, including very turbid waters, historical impacts of anthropocentric origin; both industrial and maritime (remnants of boats and equipment) scattered on the coast can be observed. The impact was estimated as low to medium, partial, immediate and brief, while at Caobita beach, there was slight impact of the waves on the coast, with low contribution and deposit of white sands on the frontal dune. The erosion band on the beaches here was minimal due to the presence of a sound reef barrier and the protection of the prevalent storm winds. And surf by the Punta Martin Garcia, the impact found here was low, partial, immediate and brief.

In Barahona province, Enriquillo and Patos beaches had little disturbance. These beaches are formed by boulders and are in a very high energy zone. There were slight effects of wind on the vegetation that borders the Patos river. There was turbidity of marine waters, intense swell and reduction of fishing. The impact here found was low, partial, immediate and brief. In Carmen and Punta Blanca beaches, there was a slight impact of erosion and mangrove bearing by the storm, although there was destruction of mangrove by anthropocentric origin. In the fishermen landing area, there was a lot of impact and plastic garbage accumulated. The impact was low to medium, partial, immediate and brief. Most of these beaches of Barahona are oriented towards the east. The prevalent winds during the storm had a west to east direction. Thus, these beaches were leeward oriented and suffered a reduce wind and wave impact.

In Pedernales province, at the Laguna de Oviedo, observations were conducted at Mosquea and Bucan beaches. These presented impacts on the dunes were made by the strong storm surge, being evident by the large accumulation of plastics, solid wastes, as well as debris from land and sea vegetation remains. The impact was considered as medium to high, partial, immediate and persistent. This site was affected, no matter that the location faces away from the main currents and wave patterns; it has a leeward oriented 
coastline from the prevalent winds of this storm. At Bahía de las Aguilas beach, the locality was oriented seaward from the prevalent wind of this storm, suffered severe impacts from sea surge and waves, affecting the benthic communities located on a distance more than $100 \mathrm{~m}$ from the shore and some 4 $\mathrm{m}$ deep. Erosion of the beach sand was generated, transporting and depositing beyond the frontal dune, as well as flooding with sea water of the posterior lagoon. There was a large amount of marine grasses, detached from the bottom and thrown to the shore, mainly Syringodium sp. and Thalassia sp., as well as loss of littoral vegetation and affection to the scenery due impacts, discoloration and defoliation of vegetation. More severe damage occurs in older, bolder trees, thus reducing the complexity of the forest, although it seems to favor an abundant regeneration of some young individual's tree species. The effect of the hurricane was very evident on the sponge communities. Remains of these invertebrates were seen thrown into the top of the dune, the cliffs on the entire length of the beach. The site was originally very rich in sponges growing in shallow waters $(<10 \mathrm{~m})$. The impact on that community was striking. Being more evident the damage on erect forms of sponges' detachment at their base, in this case, all forms and species of sponges were affected, regardless of the shape. Also, groups of sessile organisms affected were soft and stony corals, mainly small sizes. Other groups of the marine biota concerned are bivalve mollusks and gastropods, as well as sea urchins and starfish. These were transported by the currents, winds and breaking waves, all these remains were deposited in large amounts at the shoreline, creating large mats at the water edge, as well as at the top of the dunes and on top of the rocky shores here found. It is notorious the presence of queen conch shells (lambies), mainly juveniles and small sizes. The impact was estimated to be very high, critical, immediate and persistent. On the cliffs, north of Bahia de Las Aguilas beach, the most noticeable effect is the impact of storm surge on rocks, the effect over the typical cliff vegetation and the accumulation of large numbers of sea grasses debris on the rocks cracks. In the submerged part, there was a great growth of green-blue algae. During the passage of a hurricane, maybe caused by variations in nutrients flux, due to the abnormal movement of water and sediments re-suspension and concentrations of nutrient follow, it stimulates primary and bacterial growth, specially specific undetermined (in this case) of micro algae and phytoplankton. In this area, the impact was high to very high, critical, immediate and persistent.

At the beaches and mangroves of Cabo Rojo, the effects of the waves on the coast generated erosion and loss of sand. Erosion of the berms and their deposit beyond the frontal dune cause that material (sand) to be integrated into the mud of the mangrove forest nearby. Swamps behind the dune area were flooded; mangroves and wetland trees were defoliated and some were uprooted with the consequent injury to biomass. It was also found displacement and disturbance of seabirds (nesting and resting places) and accompanying biota, damages to sea grass meadows, including sea urchins, stars, crabs, lobsters and mollusks. Severe damage was found on shallow marine grasses, with the destruction and subsequent sedimentation to those that were not uprooted. In this area, the impact is high to very high, critical, immediate and persistent. On the waterfront of the city of Pedernales and Playa Pedernales, the breaking waves caused damages, impacted structures and weaken the foundations of the wall of the walk way and street. It caused damage and loss of coastal trees (almond trees, beach grapes), and collapsed some small buildings. There was visible beach erosion caused by the waves and accumulation of rocks and lacking of sand from the beach. The impact is low to medium, partial, immediate and brief.

Coastal biodiversity in the tropics, including mangroves, sea grass and coral reefs, ecosystems that are very rich in invertebrates, fish and marine plants 
[22]. These ecosystems are threatened by diverse causes, including natural events of varying magnitude and human impact. Amongst all, the first are hurricanes (or cyclones) and are characterized by intense winds, high waves and intensity, whose effects have an impact on marine and coastal biodiversity, including sediment suspension, fracture of hard organisms and drag of fragments or complete organisms that cannot escape the vigorous movement of water. The human impact is linked to our population expansion, transforming the landscape, modifying ecosystems, providing nutrients through drainage, introducing pollutants and causing global changes in temperature [23, 24]. The impact of a cyclone can transform into, one day, the distribution and abundance of organisms and generate very different patterns and, in the longer term, these destructive episodes promote evolutionary changes in the ecosystem [25, 26].

Although marine and coastal ecosystems have weathered some massive extinction events and impacts, their future is bleak because global warming will raise the mean sea level and we will have higher periods with high temperatures, which would promote greater frequency and intensity of storms and hurricanes, and this could diminish the capacity for reconstruction and growth of coastal and marine communities [27-29]. Additionally, society have increased the commercial and recreational use of the coast, both of which have impacted this region and in cases have caused great damage, mainly near those densely populated areas. Global effects of these changes have an impact on biodiversity and coastal ecosystems.

Dominican Republic's coastal zone is in the natural path of natural catastrophic weather events, such as hurricanes, storms, strong waves and rising sea levels. Coastal areas and marine ecosystems have suffered from natural causes, and continue to face impacts, degradation and decline in its functions, thus reducing the benefits that they bring. At present, Dominican coastline and its environments, additionally, are facing negative impacts and alterations due to anthropic development, which has reduced resilience and adaptability of its biodiversity [30-33].

\section{Conclusions}

In general, it was found that the main hurricane Matthew effects on the south coast of the Dominican Republic were due to high seas, including surges and strong currents created by the storm, which affected nearshore ecosystems and coastal communities and proprieties. In this work, the degree of destruction has been defined according to the classification of the typology of impacts, allowing understanding the various types and degrees of environmental effects.

This protocol of analysis can be used in combination with the characteristic of shoreline, to determine the degree of environmental effects that coastline can suffer. In cases where there is already an impact present, it can be used to determine its environmental fragility, vulnerability level and susceptibility of environment to be impaired by the incidence of certain impacts. It was evident throughout the analysis that hurricanes effects transformed coastal ecosystems, the distribution and abundance of organisms and generated changes in the biodiversity patterns previously found.

It is estimated that coastal ecosystems and biodiversity will be significantly affected by future climate changes. The only alternative is to establish plans for integrated coastal and marine resources management, an adequate administration and in accordance with the natural characteristics of coastal region. The conception of integrated development must be fundamental principles of conservation of natural resources and sustainable use.

\section{Acknowledgments}

The present study is a rapid report, part of an assessment, which is executed at CIBIMA, Faculty of Sciences of UASD, Dominican Republic, within the 
project entitled Biodiversity Indicators, Values and Functions Ecosystem on the Coast of Dominican Republic, FONDOCYT 2014-2B2-079.

\section{References}

[1] D'Anghera, P. M. 2004. De Orbe Novo: The Eight Decades of Peter Martyr D'Anghera, translated by MacNutt, F. A. The Project Gutenberg EBook. Accessed June 15, 2016. http://www.gutenberg.org/files/ 12425/12425.txt.

[2] De Las Casas, B. 1517. History of the Indies (Hispania Victrix). Barcelona, Spain: Iberica. (in Spanish)

[3] Oviedo, F. G. 1851. General and Natural History of the Indies. Madrid, Spain: Academy Press, 146. (in Spanish)

[4] National Hurricane Center. 2016. National Weather Service, Miami-South Florida Forecast Office, Florida International University in Miami, FL. http://www.nhc.noaa.gov.

[5] Center for Marine Biology Research (CIBIMA). 1978. Conservation and Eco-development. Science and Technology Collection, UASD. Santo Domingo: Editora Alga \& Omega, 533. (in Spanish)

[6] Center for Marine Biology Research (CIBIMA). 1994. Preliminary Study on the Coastal and Marine Biodiversity of the Dominican Republic. Santo Domingo: Editora Alfa \& Omega, 459. (in Spanish)

[7] Geraldes, F. X., and Vega, M. 2001. Manual of Methods for the Study and Monitoring of Tropical Marine Coastal Ecosystems. Santo Domingo, RD: MAMMA Foundation Inc., the Nature Conservancy, USAID/PRONATURA, 158. (in Spanish)

[8] Spellerberg, I. 1994. Monitoring Ecological Change. New York, USA: Cambridge University Press, 334.

[9] Conesa, F. V. 1997. Methodological Guide for the Evaluation of the Environmental Impact. 3rd ed.. Madrid: Mundi Press, 412. (in Spanish)

[10] Conesa Fernández-Vítora, V. 1997. Environmental Audits. Methodological Guide. 2nd ed.. Madrid: Mundi Press, 552. (in Spanish)

[11] Davis, G. E., Loope, L. L., Roman, C. T., Smith, G., Tilmant, J. T., and Soukup, M. 1996. Effect of Hurricane Andrew on Natural and Archeological Resources. Technical Report NPS/NRGCC/NRTR/96-02. U.S. Department of the Interior, National Park Service, Natural Resource Program Center, Denver, Colorado.

[12] Paerl, H. W., Bales, J. D., Ausley, L. W., Buzzelli, C. P., Crowder, L. B., Eby, L. B., Fear, J. M., Go, M., Peierls, B. L., Richardson, T. L., and Ramus, J. 2001. "Ecosystem Impacts of Three Sequential Hurricanes (Dennis, Floyd, and Irene) on the United States' Largest Lagoonal Estuary, Pamlico Sound, NC." Proceedings of the
National Academy of Sciences of the United States of America 98 (10): 5655-60.

[13] Mallin, M. A., and Corbett, C. A. 2006. "How Hurricane Attributes Determine the Extent of Environmental Effects: Multiple Hurricanes and Different Coastal Systems.” Estuaries and Coasts 29 (6): 1046-61.

[14] Bouchon, C., Bouchon-Navaro, Y., Imbert, D., and Louis, M. 1991. "The Effect of Hurricane Hugo on the Coastal Environment of Guadeloupe Island (FWI).” Ann. Inst. Oceanogr. 67: 5-33.

[15] Massel, S. R., and Done, T. J. 1993. "Effects of Cyclone Waves on Massive Coral Assemblages on the Great Barrier Reef: Meteorology, Hydrodynamics and Demography.” Coral Reefs 12: 153-66.

[16] Rogers, C. S. 1993. "Hurricanes and Coral Reefs: The Intermediate Disturbance Hypothesis Revisited.” Coral Reefs 12: 127-37.

[17] Rogers, C. S., Suchanek, T. H., and Pecora, F. A. 1982. "Effects of Hurricanes David and Frederic (1979) on Shallow Acropora palmata Reef Communities, St. Croix, U.S. Virgin Islands.” Bull. Mar. Sci. 32 (2): 532-48.

[18] Woodley, J. D., Chornesky, E. A., Clifford, P. A., Jackson, J. B. C. , Kaufman, L. S., Knowlton, N., Lang, J. C., Pearson, M. P., Porter, J. W., Rooney, M. C., Rylaarsdam, K. W., Tunnicliffe, V. J., Wahle, C. M., Wulff, J. L., Curtis, A. S. G., Dullmeyer, M. D., Jupp, B. P., Koehl, M. A. R., Neigel, J., and Sides, E. M. 1981. "Hurricane Allen's Impact on Jamaican Coral Reefs." Science 214 (4522): 749-55.

[19] Rogers, C. S., McLain, L. N., and Tobias, C. R. 1991. "Effects of Hurricane Hugo (1989) on a Coral Reef in St. John USVI.” Mar. Ecol. Prog. Ser. 78: 189-99.

[20] Lirman, D., and Fong, P. 1996. "Sequential Storms Cause Zone-Specific Damage on a Reef in the Northern Florida Reef Tract: Evidence from Hurricane Andrew and the 1993 Storm of the Century.” Fla. Sci. 59: 50-63.

[21] Kaufman, L. S. 1983. "Effects of Hurricane Allen on Reef Fish Assemblages near Discovery Bay, Jamaica, West Indies.” J. Mar. Res. 44: 119-48.

[22] Salazar-Vallejo, S. I., and González, N. E. 1993. "Panorama and Foundations for a National Program." In Marine and Coastal Biodiversity of Mexico, edited by Salazar-Vallejo, S. I., and González, N. E. Mexico: CONABIO and CIQRO, 6-38. (in Spanish)

[23] Cortés, J. 1997. "Status of the Caribbean Coral Reefs of Central America.” In Proceedings of the 8th International Coral Reef Symposium, 1: 335-40.

[24] Jackson, J. B. C. 2001. "What Was Natural in the Coastal Oceans?” Proc. Natl. Acad. Sci. 98 (10): 5411-8.

[25] Boero, F. 1996. "Episodic Events: Their Relevance to Ecology and Evolution.” PSZN: Mar. Ecol. 17 (1-3): 237-50. 


\section{Coast of Dominican Republic}

[26] Scheffer, M., Carpenter, S., Foley, J. A., Folke, C., and Walker, B. 2001. "Catastrophic Shifts in Ecosystems." Nature 413 (6856): 591-6.

[27] Salazar-Vallejo, S. I. 1998. "Global Warming and Coastal Effects.” AvaCient 25: 10-20. (in Spanish)

[28] Done, T. J. 1999. "Coral Community Adaptability to Environmental Change at the Scales of Regions, Reefs and Reef Zones.” Amer. Zool. 39: 66-79.

[29] Knowlton, N. 2001. "The Future of Coral Reefs." Proc. Natl. Acad. Sci. 98: 5419-25.

[30] Woodley, J., Alcolado, P., Austin, T., Barnes, J., Claro-Madruga, R., Ebanks-Petrie, G., Estrada, R., Geraldes, F., Glasspool, A., Homer, F., Luckhurst, B., Phillips, E., Shim, D., Smith, R., Sealey, K. S., Vega, M., Ward, J., and Wiener, J. 2001. "Status of Coral Reefs in the Northern Caribbean and Western Atlantic Node of the GCRMN.” In Status of Coral Reefs of the World: 2004, edited by Wilkinson, C. GCRMN, ICRI, Reef Check,
AIMS, SIDA, US Coral Reef Task Force. Townsville, Queensland, Australia: Australian Institute of Marine Science.

[31] Geraldes, F. X. 2002. "Preliminary Analysis of the Economic Value of Environmental Services of Coastal Marine Ecosystems and Their Associated Resources in Tropical Islands: Case of the Dominican Republic.” In Proceedings of IV Inter-American Dialogue on Water Management, Brazil, 29. (in Spanish)

[32] Pugibet, E. 2009. Service Values of the Coastal Ecosystem in El Parque Nacional del Este, Dominican Republic. Final Project Report (ReefFix). Thematic Network of Protected Areas (PATN), Inter-American Biodiversity Information Network (IABIN), OAS, 27. (in Spanish)

[33] Geraldes, F. X. 2003. "Coral Reefs of Dominican Republic.” In Latin American Coral Reefs, edited by Cortes, J. Amsterdam, the Netherlands: Elsevier Science. 